\title{
Development and Effects of a Mechanical Ventilation Education Program with Blended Learning for Nursing Students
}

\author{
Yeom, Gye Jeong ${ }^{1) \odot} \cdot$ Yang, Jeongha ${ }^{2) \odot} \cdot$ Kim, Jihyun ${ }^{2) \odot} \cdot \mathrm{Kim}$, Hyun Sook ${ }^{3) \odot ~}$
}

Purpose: This study describes the development and implementation of a mechanical ventilation education program with a blended learning method for nursing students. Methods: Sixty-five nursing students were recruited either to the experimental group $(n=33)$ or to the control group $(n=32)$ in May 2020. This program was developed based on the analysis, design, development, implementation, and evaluation model. The analysis phase consisted of a literature review, expert consultations, and target group survey. In addition, learning objectives and a structure were designed, and an online program was developed. In the implementation phase, the program was conducted over the course of 2 weeks. The evaluation phase involved verification of the effects of the program on knowledge of mechanical ventilation, self-confidence, and ventilator nursing skills performance, as well as an assessment of satisfaction with the program. Results: The experimental group had significantly higher scores on knowledge of mechanical ventilation ( $\mathrm{t}=4.29, p<.001)$, self-confidence $(\mathrm{t}=2.31, p=.024)$, and ventilator nursing skills performance $(\mathrm{t}=4.65, p<.001)$ than the control group. Conclusion: The results indicate that this mechanical ventilation education program with blended learning was effective in meeting the needs of nursing students and can be widely used in this context.

Key Words: Education; Learning; Nursing; Students; Ventilation

Received Mar 11, 2021 Revised Jun 23, 2021 Accepted Aug 12, 2021

Corresponding author: Yang, Jeongha https://orcid.org/0000-0001-5454-8440

Department of Nursing Science, JEI University

178 Jaeneung-ro, Dong-gu, Incheon 22573, Korea

Tel: +82-32-890-7322, Fax: +82-32-890-7199, E-mail: jhyang@jeiu.ac.kr 


\section{INTRODUCTION}

Mechanical ventilation should be applied to patients with respiratory failure who are unable to breathe spontaneously and exchange gas. The function of the mechanical ventilator is to maintain gas exchange and meet the patient's metabolic requirements by regulating pressure or tidal volume [1]. Therefore, nurses must have specialized knowledge and skills related to mechanical ventilator management in order to care for severely ill patients with respiratory failure, and should be well trained from the time they are students. Before practicing in the intensive care unit, nursing students must be trained in advance knowledge and skills on unfamiliar machines such as ventilators to gain a positive practice experience [2]. Essential knowledge for mechanical ventilation includes respiratory system anatomy, physiology, artery blood gas analysis (ABGA), ventilator settings, mode types, complication prevention, and alarm sound response. Its content is broad and professional [3]. Nurse's skills, such as connecting circuits correctly, ensuring the appropriate mode for the patient, and responding to alarms immediately, are critical to keeping patients safe. Thus, this ability can prevent problems such as airway aspiration and ventilator-related pneumonia [4]. In previous studies related to mechanical ventilation education, information on infection management related to ventilators was available for students and clinical nurses, as well as web-based learning and simulations for students [5-13]. However, there were limitations in improving performance ability through online learning. Also the simulation practice did not have enough time for pre-learning.

Blended learning is an education method that combines the advantages of online and offline instruction. The advantage of face-to-face education is realistic interaction, and the advantages of online education are that group class time is minimized and prior learning or review is possible without time and space constraints [14]. For students who are proficient in information technology, the combination of online education using the university's learning management system (LMS) and practice education is an effective teaching method. Mechanical ventilation education should not only convey knowledge but also provide opportunities for hands-on practice. To raise the cognitive domain of educational goals to a higher level of application, analysis, and evaluation, mechanical ventilation instruction should be given using as a learning method with which learners can talk, think, and perform a lot [15]. However, blended learning, which is a combination of online and face-to-face learning, is suitable for learning complex and specialized knowledge and skills such as ventilator management, but research on such blended learning related to mechanical ventilation is absent. It is necessary to develop effective teaching methods for nursing students who do not have experience or training in ventilator management [16]. Therefore, this study would develop a mechanical ventilation education program with blended learning that enables nursing students to systematically acquire knowledge and nursing skills according to their needs. The program developed in this study could be used for practice in critical care nursing. An improvement in students' confidence will also result. The hypotheses of this study are as follows.

- Hypothesis 1. The experimental group with blended learning will have a higher level of knowledge of mechanical ventilation than the control group with online education only.

- Hypothesis 2. The experimental group with blended learning will have higher self-confidence level than the control group with online education only.

- Hypothesis 3. The experimental group with blended learning will have a higher level of ventilator nursing skills performance than the control group with online education only.

\section{METHODS}

\section{Study Design}

This study was a quasi-experimental design and nonequivalent comparison group before and after design to verify the effect of a ventilator-education program using a blended learning method for nursing students.

\section{Participants}

Subjects were students who took a course in the "adult healthy nursing" curriculum, including theory about respiratory disease and mechanical ventilation, at a college located in Incheon. Students in their 4rd year who were scheduled to practice in an intensive care unit (ICU) were recruited. The effect size was set to .70 based on mean difference between groups divided by standard deviation from result of a previous study [17]. Using $\mathrm{G}^{*}$ power program 3.1.9 and with a power (1- $\beta$ ) of .80, a significance level of .05, and an effect size of .70, two-tailed independent t-test resulted in a sample size of 34 people per group. Convenience sampling was performed by the researcher in each of 4 practice groups of less than 20 people. Initially, 70 people participated. However, five subjects did not re- 


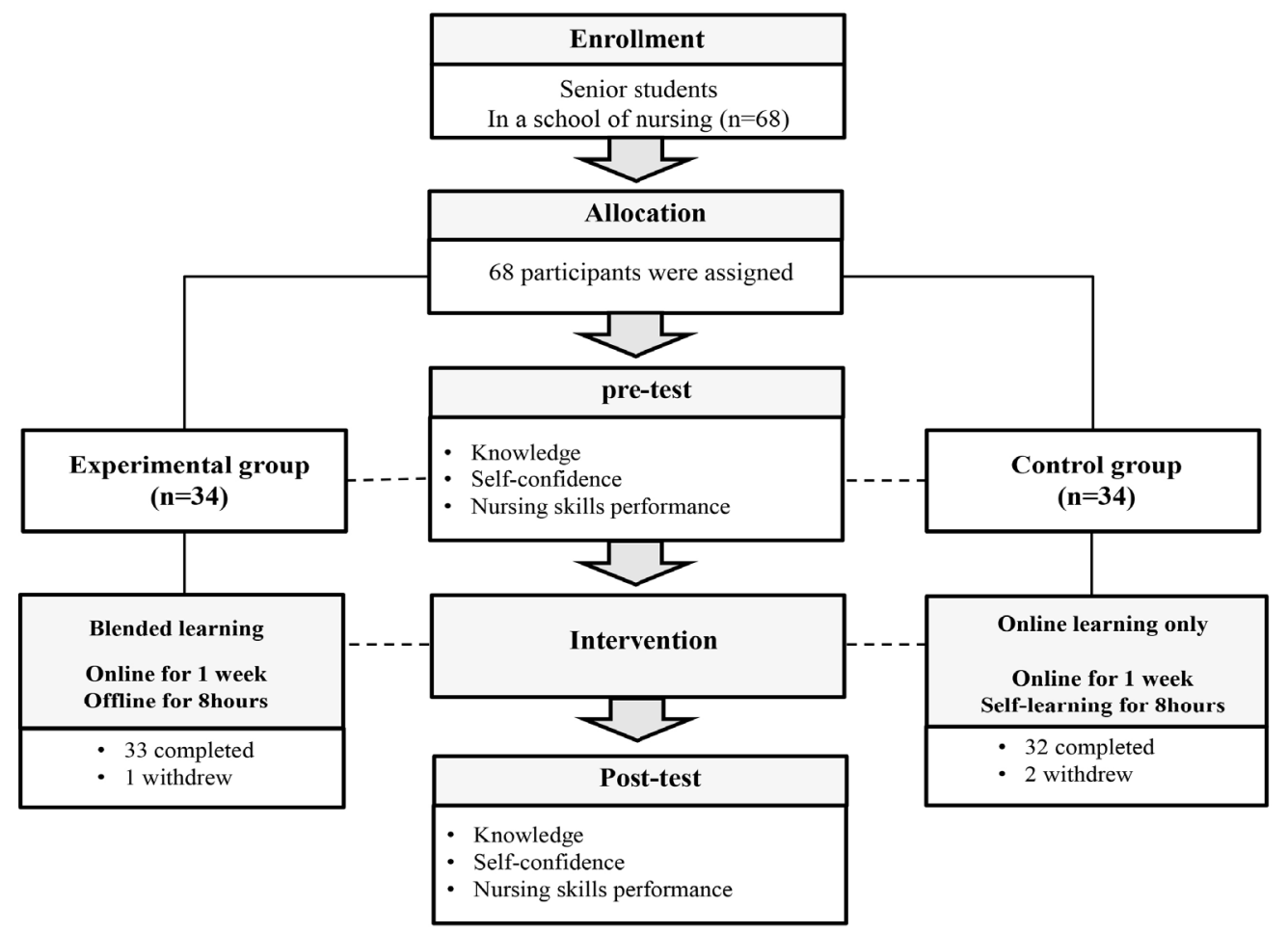

Figure 1. Flow diagram of the study participants.

spond to the follow-up. The reasons for dropping out were all personal circumstances, such as job interviews. Therefore, 33 subjects in the experimental group with blended learning and 32 subjects in the control group with online education only were included in the final analysis (Figure 1).

\section{Development Procedure}

This program was developed based on the analysis, design, development, implementation, and evaluation (ADDIE) model (Figure 2). This is a procedural model used for instructional systems design (ISD) and is the most basic model used to achieve an efficient and attractive teaching system based on learner's needs [18].

\section{1) Analysis}

Literature review. After searching for "ventilator" or "blended learning" in domestic and international academic search engines (KISS, DBpia, CINAHL, MEDLINE), 34 domestic and 29 foreign studies were reviewed to analyze the contents and methods of education, educational demand, and influencing factors. As a result of a literature review, there were educational research on ventilator-related infection management [5-7], web-based ventilator education program [8-10], and simulation education pro- gram [11-13]. Also, it was confirmed that blended learning is a teaching method that can efficiently utilize learning time and increase learner satisfaction. Therefore, it was decided to apply blended learning as a teaching method to improve ventilator-related knowledge and skills.

Expert group advisory. The researchers asked for advice from a group of experts. Three adult nursing professors and two advance practice nurses (APNs) in critical care nurse team, provided advice on the content and direction of the mechanical ventilation education program. After the contents of the advisory were reviewed, it was suggested that ventilator education is an essential topic for nursing students and is a core skill that is essential in the field. In addition, the researchers and experts agreed that conducting the education program at a time when various mechanical ventilators had recently been developed and used was timely. Experts said that it was necessary to apply and construct a teaching method that allows students to fully understand basic concepts and terms and learn repeatedly. After analyzing the existing website and videos related to ventilator education to determine the program's primary content, a secondary expert consultation was requested to insert and modify additional contents, select measurement tools, and distribute offline and online contents. 


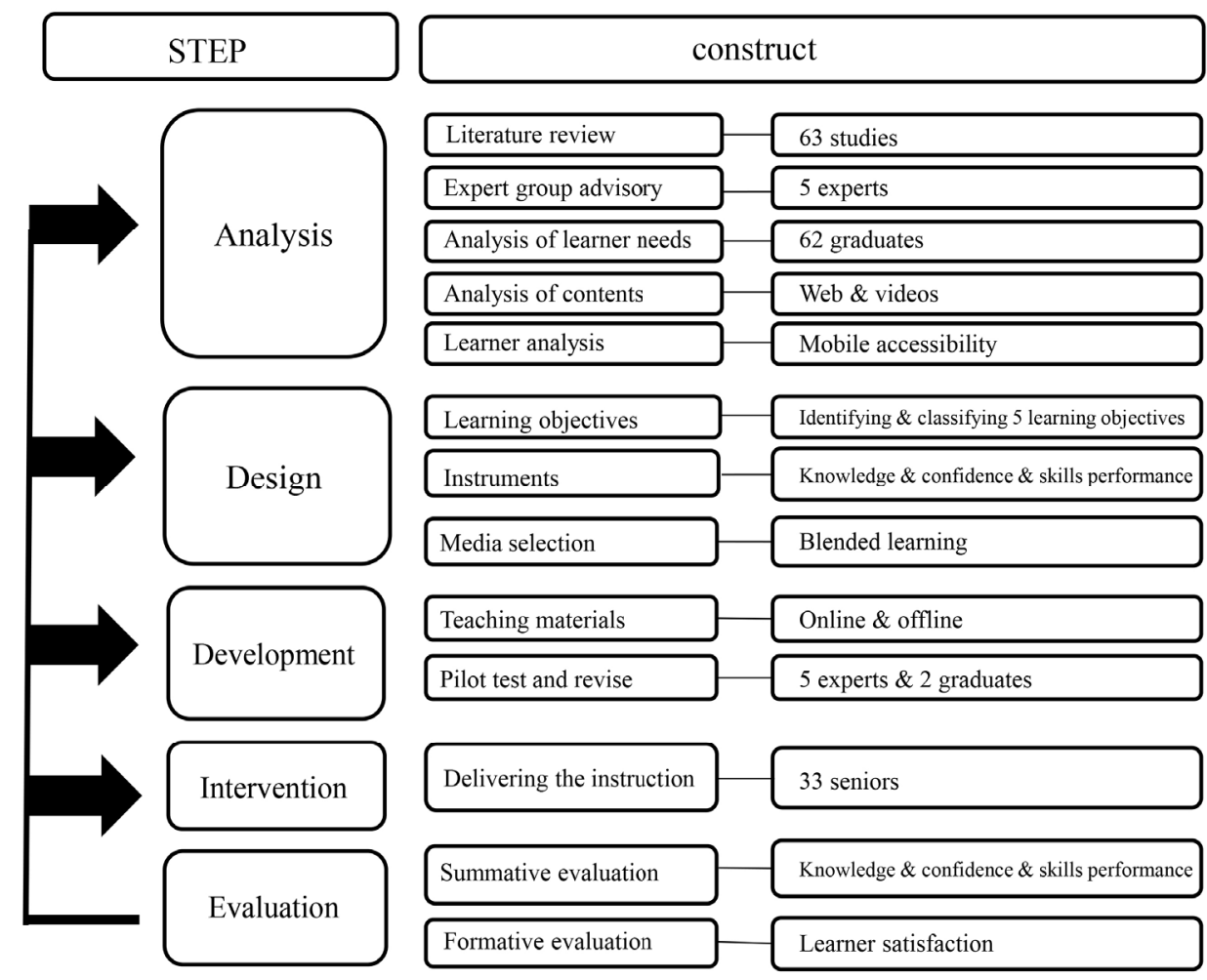

ADDIE=Analysis, design, development, implementation, and evaluation.

Figure 2. ADDIE blended learning model.

Analysis of learner needs. In order to compose the education content, difficulty, and method desired by the learner, the learner needs were first investigated. In February 2020 , a survey was conducted with 62 graduates who had already completed the fourth-year curriculum. The survey items addressed the necessity, contents, and method of ventilator training. The analysis results showed that $90.3 \%$ of the respondents recognized that ventilator training was necessary. For particularly difficult parts, such as understanding ABGA and applying ventilator nursing skills, they wanted an educational composition including videos and hands-on practice.

Analysis of existing website and videos. Prior to the design of the LMS for online learning and the production of videos, the previously produced videos and websites were analyzed. The educational website operated by the domestic nursing college was mainly to provide knowledge, and the YouTube videos produced by the institution were the level of explaining the operation method for medical personnel. They were collected for analysis of educational topics, content development methods, and planning intentions. Since it was confirmed that all students owned smartphones, it was possible to post study materials through
LMS, check student attendance, and check assignments.

\section{2) Design}

Learning objectives. Based on the results of the analysis phase, five objectives for mechanical ventilation education were set for college students, and a total of 14 subgoals to be performed were also set (Table 1).

Assessment instruments. To evaluate whether the learner had reached 5 objectives, instruments developed by this researcher.

Media selection. It was selected as a blended learning teaching method that combines online and offline learning.

\section{3) Development}

Development and production of teaching materials.

- Text \& videos: Text data on respiratory physiology and ventilator management were loaded into the LMS of the researcher's university. It summarizes a large number of learning ranges and helps to repeat learning. Two lecture videos created by this researcher (ABGA, ventilator terminology) and one video demonstration by the researcher (ventilator nursing skills) were loaded into the LMS. 
- Quiz \& Q\&A: Learners can repeat the quiz at any time by accessing LMS. This helps with learning difficult concepts or terms. In the online Q\&A section, the researcher answered any questions that learners asked.

- Mechanical ventilator \& operation manual: A portable ventilator (model: MTV 1000) provided at the university to which this researcher belongs was used.

- Simulator: To serve as a patient to connect with the ventilator, SimMan $3 \mathrm{G}$ of Laerdal $^{\mathrm{TM}}$ products in the nursing lab of the university to which this researcher belongs was utilized.

- ABGA result sheet \& hand-over notes: The person in charge of the next shift was given the details of the patient during hand-over, including the patient's condition and test results.

Pilot test and revise. After two graduates reviewed the material primarily using the developed online texts and videos, we received feedback on the degree of understanding and difficulty, typos, terms, and images. The contents of the program were finalized after deliberation among the researcher, three nursing professors, and two APNs.

\section{4) Intervention}

The experimental group was provided with 1 week of online learning and 8 hours of offline learning from July
13, 2020 to July 23, 2020 and the control group was provided with 1 week of online learning and 8 hours of selflearning from July 6, 2020 to July 16, 2020. In order to minimize contamination between groups, the intervention was applied to the experimental group after 1 week.

First, to achieve the learning objectives, online learning is developed in the form of text, videos, quiz, Q\&A, operation manual, and performance checklist and then uploaded to LMS. The researcher notified both groups to do online learning for a week and guided them to the learning method. Researcher encouraged students to complete their learning 2 hours a day while checking their learning status. So all the students studied at least 10 hours in a week.

After a week of online learning, researchers provided an offline learning (hand-over, simulation, and peer learning) and follow-up activities (analysis of test results, manual learning, operation, and writing a reflection on one's feelings) to the experimental group in a practice room of the college for 8 hours. The simulation was conducted so that the students practiced the procedure repeatedly. Peer learning was shared with peer students to perform practice and handover. The two practice groups of less than 20 people who were sampled in the experimental group, each received offline learning on different days.

After a week of online learning, the control group performed an self-learning under the supervision of a prac-

Table 1. Structure of the Education Program with Blended Learning for Nursing Students

\begin{tabular}{|c|c|c|c|c|c|}
\hline Objectives & Sub-goals & Online (LMS) & Offline & Follow-up activities & Evaluation \\
\hline $\begin{array}{l}\text { Understanding } \\
\text { respiratory } \\
\text { physiology }\end{array}$ & $\begin{array}{l}\cdot \text { Ventilation } \\
\cdot \text { Gas exchange } \\
\cdot \text { Flow rate }\end{array}$ & $\begin{array}{l}\cdot \text { Text } 1 \\
\cdot \text { Quiz } \\
\cdot \text { Q\&A }\end{array}$ & - & - & Knowledge (3 items) \\
\hline $\begin{array}{l}\text { Understanding } \\
\text { ABGA }\end{array}$ & $\begin{array}{l}\cdot \text { Acid/ base } \\
\cdot \text { Compensation } \\
\text { mechanism } \\
\cdot \text { Interpretation }\end{array}$ & $\begin{array}{l}\cdot \text { Video } 1 \\
\cdot \text { Quiz } \\
\cdot \text { Q\&A }\end{array}$ & · Hand over & $\begin{array}{l}\text { Analysis of test } \\
\text { results }\end{array}$ & Knowledge (6 items) \\
\hline $\begin{array}{l}\text { Understanding } \\
\text { ventilator } \\
\text { terminology }\end{array}$ & $\begin{array}{l}\cdot \text { Setting } \\
\cdot \text { Mode } \\
\cdot \text { Alarm }\end{array}$ & $\begin{array}{l}\cdot \text { Video } 2 \\
\cdot \text { Quiz } \\
\cdot \text { Q\&A }\end{array}$ & - & & Knowledge (5 items) \\
\hline $\begin{array}{l}\text { Understanding } \\
\text { ventilator } \\
\text { management }\end{array}$ & $\begin{array}{l}\text { - General nursing } \\
\text { - Complication }\end{array}$ & $\begin{array}{l}\cdot \text { Text } 2 \\
\cdot \text { Q\&A }\end{array}$ & - & - & Knowledge (6 items) \\
\hline $\begin{array}{l}\text { Applying } \\
\text { ventilator } \\
\text { nursing skills }\end{array}$ & $\begin{array}{l}\cdot \text { Preparations } \\
\cdot \text { Intervention } \\
\cdot \text { Evaluation }\end{array}$ & $\begin{array}{l}\cdot \text { Video } 3 \\
\cdot \text { Operation } \\
\text { manual } \\
\cdot \text { Performance } \\
\text { checklist }\end{array}$ & $\begin{array}{l}\cdot \text { Simulation } \\
\cdot \text { Peer learning }\end{array}$ & $\begin{array}{l}\cdot \text { Manual learning } \\
\text { - Operation }\end{array}$ & $\begin{array}{l}\cdot \text { Self-confidence }(10 \text { items }) \\
\cdot \text { Ventilator nursing skills } \\
\text { performance ( } 20 \text { items) }\end{array}$ \\
\hline Summary & & & & $\begin{array}{l}\text { Writing a reflection } \\
\text { on one's feelings }\end{array}$ & Satisfaction (4 items) \\
\hline
\end{tabular}

LMS=Learning management system. 
tical assistant in a practice room of the college for 8 hours. During self-learning, online learning was repeated and follow-up activities were performed individually. Also the two practice groups of less than 20 people who were sampled in the control group, each received self-learning on different days. The composition and contents of the program are presented in Table 1.

\section{5) Evaluation}

To evaluate the learner satisfaction, 65 subjects were surveyed for learner satisfaction with four questions immediately after the end of the intervention period. The satisfaction of the experimental group had an average score of $4.64 \pm 0.78$ points (out of 5 points), and that of the control group had an average score of $4.34 \pm 0.79$ points $(\mathrm{t}=1.50$, $p=.138$ ). The satisfaction of the experimental group with the amount and time of learning had $4.52 \pm 0.80$ points, and that of the control group had $3.91 \pm 0.93$ points $(t=2.84, p=$ .006). The satisfaction of the experimental group with the composition and difficulty level of contents had $4.73 \pm 0.45$ points, and that of the control group had $3.97 \pm 0.74$ points $(\mathrm{t}=5.00, p<.001)$. The most interesting parts of the experimental group were applying ventilator nursing skills in hands-on practice $(46.2 \%)$ and the video related to ventilator nursing skills (23.1\%).

\section{Measures}

\section{1) Knowledge of ventilator}

Knowledge of mechanical ventilation instruments is addressed by multiple-choice questions developed by a researcher in the course of the development of this educational program. Based on the sub-goals of the program, the item-content validity index (I-CVI) of 5 experts ( 3 adult nursing professors and $2 \mathrm{APNs}$ ) is calculated. The final 20 questions were selected because, after being tested for content validity again, they had a value of .80 or higher. The subarea of the instrument consisted of respiratory physiology, ABGA, ventilator terminology, and ventilator management. This instrument gives 1 point for a correct answer and 0 points for an incorrect or unknown answer. The scale ranges are 0 points for the minimum value and 20 points for the maximum value. The higher the score is, the higher the degree of the subject's knowledge related to mechanical ventilation is. The internal reliability, KuderRichardson 20, of this scale was 84 .

\section{2) Self-confidence}

The ventilator nursing practice self-confidence instrument was developed by a researcher during the course of this educational program's development. Based on the sub-goals of the program, 5 experts' I-CVIs were calculated, and the final 10 questions were adopted. The ventilator nursing practice confidence instrument is a 10-point scale consisting of explanation, assessment, and intervention. The minimum value is 0 points, and the maximum value is 100 points. The higher the score is, the higher the subject's self-confidence is. The internal reliability or Cronbach's $\alpha$ of this scale was 96 .

\section{3) Ventilator nursing skills performance}

The ventilator nursing skills performance instrument is a checklist developed by a researcher during the course of developing this educational program. Based on the subgoals of the program, the I-CVIs of 5 experts are calculated. The final 20 questions were consisted of preparation, intervention, and evaluation. Each question was rated on a 2-point scale, with 0 points for "not performed," 1 point for "partially performed," and 2 points for "performed enough." The scale ranged from 0 to 40 , and the higher the score is, the higher the subject's performance ability is. Two evaluators measured each and calculated an average value. Intra-class correlation (ICC), comparing the measurements of the two raters, was 0.94 , and the internal reliability Cronbach's $\alpha$ of the scale was .90 .

\section{Data Collection}

The period of data collection was from May 16, 2020, to June 30, 2020. This study was conducted with the approval of the Institutional Review Board of the university in Seoul to protect the ethical concerns of study subjects (2-7001793 -AB-N-012020001HR). All the recruiters were provided with online format explanations describing voluntary participation, guarantee of anonymity, possibility of withdrawal, disadvantages, and harmlessness. The researcher obtained online informed consent from the subjects before they participated in the study. It was explained that all interventions and investigations are for research purposes and would not affect subjects' grade evaluations. The co-researchers conducted the intervention directly. Data collection and intervention providers were conducted by different researchers.

After the follow-up investigation, the control group was provided the same offline learning program. Preliminary investigations were conducted on the same day for each group, and follow-up investigations were conducted immediately after the intervention. Both pre- and post-investigation were conducted with online questionnaires, except for the ventilator nursing skills performance. To mea- 
sure the subjects' ventilator nursing skills performance, two raters scored each checklist. Researcher involved in the data analysis and two raters didn't know which group was offered intervention.

\section{Data Analysis}

Collected data were analyzed using the jamovi 1.1.9 version program. The dependent variables and the general characteristics of the subjects were analyzed using descriptive statistics. It was analyzed with an independent t-test to verify the hypothesis and prior homogeneity of the experimental and control groups.

\section{RESULTS}

\section{Homogeneities between the Experimental Group and the Control Group}

Regarding the general characteristics of study subjects, there were 15 males and 50 females. The average age of the subjects was $24.75 \pm 4.70$ years old $(t=-0.57, p=.570)$. As a result of confirming the adult nursing grade score before the study, homogeneity was secured between the two groups $(\mathrm{t}=-0.65, p=.521)$. As a result of comparing prior knowledge of mechanical ventilation $(\mathrm{t}=0.70, p=.485)$, prior self-confidence $(\mathrm{t}=-0.52, p=.606)$, and prior ventilator nursing skills performance $(\mathrm{t}=-1.34, p=.184)$ between the two groups, there was no significant difference in total scores. These results are summarized in Table 2.

\section{Testing of Hypotheses}

As a result of analyzing the collected data to test hypothesis 1 , the control group's knowledge difference between their pre- and postscores was $6.69 \pm 4.29$, and the experimental group's knowledge of mechanical ventilation difference between their pre- and postscores was 10.85 \pm 3.50 . As a result of testing differences between the two groups, the average score of the experimental group was significantly higher than that of the control group $(t=4.29$, $p<.001)$. Among the knowledge questions, subjects' scores on characteristics of ABGA $(\mathrm{t}=2.79, p=.007)$, characteristics of ventilator terminology $(\mathrm{t}=4.64, p<.001)$, and ventilator management $(\mathrm{t}=3.80, p<.001)$ were significantly higher in the experimental group, but scores were not higher for the characteristics of respiratory physiology $(\mathrm{t}=-0.85, p=.399)$ (Table 3). Thus, hypothesis 1 was supported.

As a result of analyzing the collected data to test hypothesis 2 , the self-confidence difference between the pre-

Table 2. Homogeneity Test between Experimental and Control Groups

$(N=65)$

\begin{tabular}{|c|c|c|c|c|}
\hline \multirow{2}{*}{ Variables (Range) } & Total $(N=65)$ & Exp. $(n=33)$ & Cont. $(n=32)$ & \multirow{2}{*}{$\mathrm{t}(p)$} \\
\hline & $\mathrm{M} \pm \mathrm{SD}$ & $\mathrm{M} \pm \mathrm{SD}$ & $\mathrm{M} \pm \mathrm{SD}$ & \\
\hline Age (year) & $24.75 \pm 4.70$ & $24.42 \pm 3.70$ & $25.09 \pm 5.59$ & $-0.57(.570)$ \\
\hline Adult nursing grade score $(0 \sim 100)$ & $86.80 \pm 5.89$ & $86.33 \pm 6.10$ & $87.28 \pm 5.73$ & $-0.65(.521)$ \\
\hline Knowledge of mechanical ventilation (0 20) & $7.75 \pm 3.56$ & $8.06 \pm 3.77$ & $7.44 \pm 3.36$ & $0.70(.485)$ \\
\hline Respiratory physiology (0 30) & $1.80 \pm 0.89$ & $2.00 \pm 1.00$ & $1.59 \pm 0.71$ & $1.88(.065)$ \\
\hline ABGA $(0 \sim 6)$ & $2.45 \pm 1.43$ & $2.55 \pm 1.60$ & $2.34 \pm 1.23$ & $0.57(.571)$ \\
\hline Ventilator terminology $(0 \sim 5)$ & $1.18 \pm 1.06$ & $1.15 \pm 1.09$ & $1.22 \pm 1.04$ & $-0.25(.800)$ \\
\hline Ventilator management $(0 \sim 6)$ & $2.32 \pm 1.71$ & $2.36 \pm 1.45$ & $2.28 \pm 1.97$ & $0.19(.848)$ \\
\hline Self-confidence (0 100) & $15.60 \pm 13.71$ & $14.73 \pm 14.54$ & $16.50 \pm 12.97$ & $-0.52(.606)$ \\
\hline Explanation $(0 \sim 30)$ & $4.86 \pm 4.42$ & $4.82 \pm 4.89$ & $4.91 \pm 3.96$ & $-0.08(.937)$ \\
\hline Assessment (0 20) & $3.52 \pm 3.13$ & $3.58 \pm 3.37$ & $3.47 \pm 2.92$ & $0.14(.892)$ \\
\hline Intervention $(0 \sim 50)$ & $7.22 \pm 6.92$ & $6.33 \pm 6.98$ & $8.13 \pm 6.84$ & $-1.05(.300)$ \\
\hline Ventilator nursing skills performance $(0 \sim 40)$ & $11.34 \pm 7.65$ & $10.09 \pm 7.74$ & $12.63 \pm 7.47$ & $-1.34(.184)$ \\
\hline Preparations (0 24) & $6.63 \pm 4.89$ & $5.82 \pm 5.34$ & $7.47 \pm 4.31$ & $-1.37(.176)$ \\
\hline Intervention (0 12) & $3.92 \pm 2.84$ & $3.67 \pm 2.80$ & $4.19 \pm 2.90$ & $-0.74(.464)$ \\
\hline Evaluation $(0 \sim 4)$ & $0.78 \pm 1.01$ & $0.61 \pm 0.93$ & $0.97 \pm 1.06$ & $-1.46(.148)$ \\
\hline
\end{tabular}

ABGA=arterial blood gas analysis; Cont.=control group; Exp.=experimental group. 
and postscores of the control group was $61.53 \pm 18.38$, and that of the experimental group was $72.42 \pm 19.64$. As a result of testing differences between the two groups, the average value of the experimental group was significantly higher than that of the control group $(t=2.31, p=.024)$. Among the self-confidence questions, explanation ( $\mathrm{t}=2.21$, $p=.031)$, assessment $(t=2.16, p=.034)$, and intervention $(t=$ $2.21, p=.031$ ) were significantly higher in the experimental group (Table 3). Thus, hypothesis 2 was supported.

As a result of analyzing the collected data to test hypothesis 3 , the ventilator nursing skills performance difference between the pre- and postscores of the control group was $14.86 \pm 10.71$, and that of the experimental group was $26.03 \pm 8.57$. As a result of testing differences between the two groups, the average value of the experimental group was significantly higher than that of the control group $(t=4.65, p<.001)$. Among the ventilator nursing skills performance questions, preparations ( $\mathrm{t}=4.35 p<.001)$, intervention ( $\mathrm{t}=3.49, p=.001)$, and evaluation $(\mathrm{t}=4.44, p<.001)$ were significantly higher in the experimental group (Table 3). Thus, hypothesis 3 was supported.

\section{DISCUSSION}

This program was developed according to the ADDIE model and was developed cyclically through the process of feedback conducted at each phase. An important factor in the analysis phase for educational program development was learner-analysis activities. This study has gone through literature review and surveys. In addition, the re-

Table 3. Comparison of Knowledge, Self-Confidence, and Ventilator Nursing Skills Performance between Experimental and Control Groups

$(N=65)$

\begin{tabular}{|c|c|c|c|c|c|c|}
\hline \multirow[t]{2}{*}{ Variables (possible range) } & \multirow[t]{2}{*}{ Groups } & Before & After & \multirow[t]{2}{*}{$\mathrm{t}(p)$} & $\begin{array}{c}\text { Difference } \\
\text { (After-before) }\end{array}$ & \multirow[t]{2}{*}{$\mathrm{t}(p)$} \\
\hline & & $\mathrm{M} \pm \mathrm{SD}$ & $\mathrm{M} \pm \mathrm{SD}$ & & $\mathrm{M} \pm \mathrm{SD}$ & \\
\hline $\begin{array}{l}\text { Knowledge of mechanical } \\
\text { ventilation }(0 \sim 20)\end{array}$ & $\begin{array}{l}\text { Exp. }(n=33) \\
\text { Cont. }(n=32)\end{array}$ & $\begin{array}{l}8.06 \pm 3.77 \\
7.44 \pm 3.36\end{array}$ & $\begin{array}{l}18.91 \pm 1.31 \\
14.13 \pm 3.88\end{array}$ & $\begin{array}{c}6.63 \\
(<.001)\end{array}$ & $\begin{array}{r}10.85 \pm 3.50 \\
6.69 \pm 4.29\end{array}$ & $\begin{array}{c}4.29 \\
(<.001)\end{array}$ \\
\hline Respiratory physiology (0 30) & $\begin{array}{l}\text { Exp. }(n=33) \\
\text { Cont. }(n=32)\end{array}$ & $\begin{array}{l}2.00 \pm 1.00 \\
1.59 \pm 0.71\end{array}$ & $\begin{array}{l}2.82 \pm 0.39 \\
2.59 \pm 0.50\end{array}$ & $\begin{array}{l}2.01 \\
(.049)\end{array}$ & $\begin{array}{l}0.82 \pm 0.95 \\
1.00 \pm 0.76\end{array}$ & $\begin{array}{l}-0.85 \\
(.399)\end{array}$ \\
\hline $\operatorname{ABGA}(0 \sim 6)$ & $\begin{array}{l}\text { Exp. }(n=33) \\
\text { Cont. }(n=32)\end{array}$ & $\begin{array}{l}2.55 \pm 1.60 \\
2.34 \pm 1.23\end{array}$ & $\begin{array}{l}5.58 \pm 0.66 \\
4.31 \pm 1.31\end{array}$ & $\begin{array}{c}4.89 \\
(<.001)\end{array}$ & $\begin{array}{l}3.03 \pm 1.65 \\
1.97 \pm 1.40\end{array}$ & $\begin{array}{l}2.79 \\
(.007)\end{array}$ \\
\hline Ventilator terminology $(0 \sim 5)$ & $\begin{array}{l}\text { Exp. }(n=33) \\
\text { Cont. }(n=32)\end{array}$ & $\begin{array}{l}1.15 \pm 1.09 \\
1.22 \pm 1.04\end{array}$ & $\begin{array}{l}4.73 \pm 0.52 \\
3.16 \pm 1.46\end{array}$ & $\begin{array}{c}5.74 \\
(<.001)\end{array}$ & $\begin{array}{l}3.58 \pm 1.06 \\
1.94 \pm 1.70\end{array}$ & $\begin{array}{c}4.64 \\
(<.001)\end{array}$ \\
\hline Ventilator management $(0 \sim 6)$ & $\begin{array}{l}\text { Exp. }(n=33) \\
\text { Cont. }(n=32)\end{array}$ & $\begin{array}{l}2.36 \pm 1.45 \\
2.28 \pm 1.97\end{array}$ & $\begin{array}{l}5.79 \pm 0.48 \\
4.06 \pm 1.52\end{array}$ & $\begin{array}{c}6.12 \\
(<.001)\end{array}$ & $\begin{array}{l}3.42 \pm 1.39 \\
1.78 \pm 2.04\end{array}$ & $\begin{array}{c}3.80 \\
(<.001)\end{array}$ \\
\hline Self-confidence (0 100) & $\begin{array}{l}\text { Exp. }(n=33) \\
\text { Cont. }(n=32)\end{array}$ & $\begin{array}{l}14.73 \pm 14.54 \\
16.50 \pm 12.97\end{array}$ & $\begin{array}{l}87.15 \pm 12.68 \\
78.03 \pm 14.32\end{array}$ & $\begin{array}{l}2.72 \\
(.008)\end{array}$ & $\begin{array}{l}72.42 \pm 19.64 \\
61.53 \pm 18.38\end{array}$ & $\begin{array}{l}2.31 \\
(.024)\end{array}$ \\
\hline Explanation $(0 \sim 30)$ & $\begin{array}{l}\text { Exp. }(n=33) \\
\text { Cont. }(n=32)\end{array}$ & $\begin{array}{l}4.82 \pm 4.89 \\
4.91 \pm 3.96\end{array}$ & $\begin{array}{l}26.03 \pm 3.81 \\
22.91 \pm 4.76\end{array}$ & $\begin{array}{l}2.93 \\
(.005)\end{array}$ & $\begin{array}{l}21.21 \pm 6.37 \\
18.00 \pm 5.30\end{array}$ & $\begin{array}{l}2.21 \\
(.031)\end{array}$ \\
\hline Assessment (0 20) & $\begin{array}{l}\text { Exp. }(n=33) \\
\text { Cont. }(n=32)\end{array}$ & $\begin{array}{l}3.58 \pm 3.37 \\
3.47 \pm 2.92\end{array}$ & $\begin{array}{l}17.58 \pm 2.74 \\
15.13 \pm 3.70\end{array}$ & $\begin{array}{l}3.04 \\
(.003)\end{array}$ & $\begin{array}{l}14.00 \pm 4.05 \\
11.66 \pm 4.68\end{array}$ & $\begin{array}{l}2.16 \\
(.034)\end{array}$ \\
\hline Intervention $(0 \sim 50)$ & $\begin{array}{l}\text { Exp. }(n=33) \\
\text { Cont. }(n=32)\end{array}$ & $\begin{array}{l}6.33 \pm 6.98 \\
8.13 \pm 6.84\end{array}$ & $\begin{array}{l}43.55 \pm 6.73 \\
40.00 \pm 6.52\end{array}$ & $\begin{array}{l}2.16 \\
(.035)\end{array}$ & $\begin{array}{l}37.21 \pm 10.02 \\
31.88 \pm 9.46\end{array}$ & $\begin{array}{l}2.21 \\
(.031)\end{array}$ \\
\hline $\begin{array}{l}\text { Ventilator nursing skills } \\
\text { performance }(0 \sim 40)\end{array}$ & $\begin{array}{l}\text { Exp. }(n=33) \\
\text { Cont. }(n=32)\end{array}$ & $\begin{array}{l}10.09 \pm 7.74 \\
12.63 \pm 7.47\end{array}$ & $\begin{array}{l}36.12 \pm 3.54 \\
27.48 \pm 7.96\end{array}$ & $\begin{array}{c}5.62 \\
(<.001)\end{array}$ & $\begin{array}{l}26.03 \pm 8.57 \\
14.86 \pm 10.71\end{array}$ & $\begin{array}{c}4.65 \\
(<.001)\end{array}$ \\
\hline Preparations (0 24) & $\begin{array}{l}\text { Exp. }(n=33) \\
\text { Cont. }(n=32)\end{array}$ & $\begin{array}{l}5.82 \pm 5.34 \\
7.47 \pm 4.31\end{array}$ & $\begin{array}{l}21.88 \pm 2.02 \\
17.23 \pm 4.33\end{array}$ & $\begin{array}{c}5.51 \\
(<.001)\end{array}$ & $\begin{array}{r}16.06 \pm 5.63 \\
9.77 \pm 6.05\end{array}$ & $\begin{array}{c}4.35 \\
(<.001)\end{array}$ \\
\hline Intervention (0 12) & $\begin{array}{l}\text { Exp. }(n=33) \\
\text { Cont. }(n=32)\end{array}$ & $\begin{array}{l}3.67 \pm 2.80 \\
4.19 \pm 2.90\end{array}$ & $\begin{array}{r}10.85 \pm 1.43 \\
8.03 \pm 3.21\end{array}$ & $\begin{array}{c}4.54 \\
(<.001)\end{array}$ & $\begin{array}{l}7.18 \pm 3.29 \\
3.84 \pm 4.36\end{array}$ & $\begin{array}{l}3.49 \\
(.001)\end{array}$ \\
\hline Evaluation $(0 \sim 4)$ & $\begin{array}{l}\text { Exp. }(n=33) \\
\text { Cont. }(n=32)\end{array}$ & $\begin{array}{l}0.61 \pm 0.93 \\
0.97 \pm 1.06\end{array}$ & $\begin{array}{l}3.39 \pm 0.72 \\
2.22 \pm 1.07\end{array}$ & $\begin{array}{c}5.22 \\
(<.001)\end{array}$ & $\begin{array}{l}2.79 \pm 1.25 \\
1.25 \pm 1.53\end{array}$ & $\begin{array}{c}4.44 \\
(<.001)\end{array}$ \\
\hline
\end{tabular}

$\mathrm{ABGA}=$ arterial blood gas analysis; Cont.=control group; Exp.=experimental group. 
liability of the program was increased by receiving expert advice twice during the analysis stage.

In the design stage, it was decided to apply blended learning, which was thoroughly reviewed during the analysis process. In this study, offline and online contents were appropriately distributed by applying blended learning, a teaching method that can efficiently use class time and increase student interest [14]. And the skills that require repetitive training were demonstrated by peers and practiced repeatedly so that learners' autonomy could be maximized $[19,20]$. In terms of the proportion of blended learning, this program consisted of $40 \%$ skills-oriented offline and $60 \%$ knowledge-oriented online learning.

In the development and intervention stage, text materials and videos were mounted on the LMS, and after online learning, it was done through flip learning, in which learners participated in offline classes [21,22]. Due to COVID 19 pandemic, we measured the instruments with an online questionnaire. Since the practice was originally a small study of less than 20 people, there were no difficulties in progressing according to the planned intervention. It was rather easy to apply blended learning to students who had already experienced online learning.

In the evaluation stage, the experimental group to which blended learning was applied exhibited a higher degree of knowledge after the program than the control group, with which only online learning was used, and the difference in confidence and ventilator nursing performance was significantly higher in the experimental group. In a previous study comparing clinical supervisor skills after applying blended learning and online learning to nursing students, the group's knowledge and satisfaction with blended learning was significantly higher than that of online learning [23]. And a research of blended-learning approach to public health services training resulted in a higher knowledge achievement and satisfaction level compared with a pure e-learning [24]. In addition, many studies comparing blended learning with traditional education have shown that blended learning has a positive effect on knowledge or skills of the various learning contents [25-28].

In this study, it was found that the overall satisfaction level of learning was similar for both groups. But the experimental group, which applied blended learning, was more satisfied with the amount of learning, time spent, composition and difficulty level of contents. In particular, the most interesting sections were the hands-on practice and demonstration videos related to ventilator nursing skills. The common theme of the impressions that students wrote after blended learning was that they became confident in the skills they recognized as difficult. Doing a practice activity was an educational method that achieve the most similar effect to the actual situation by performing personally, and video was a lively and excellent transmission of effective material [29]. The educational program composed by mixing them had three conditions of experiential learning: intention, structure, and context [30]. It is considered that repeat watching the instructor's demonstration videos before performing the hands-on practice can make a difference, showing that the blended learning was effectively utilized. Therefore, Blended learning provided added pedagogical value when compared to online learning in terms of teaching students ventilator nursing skills. The cons of blended learning is that designing two or more teaching methods absolutely requires the effort of an instructor. However, as it is a learning method that increases student interest and satisfaction, it should be applied widely in the future.

The limitation of this study was that it was conducted with students from a single college. Therefore, caution is needed when generalizing results of this study. In addition, since it was measured with a non-standardized scale, it is necessary to develop and apply instruments with high validity in the future. Despite the limitation, the importance of the practice-related skills has been emphasized in the nursing curriculum recently, so we propose that the program of this study can be used not only for education and study for clinical practice but also for simulation practice and core nursing skills. Furthermore, blended learning can be applied to nursing students as well as medical personnel, and there is a possibility to improve quality of care and patient safety.

\section{CONCLUSION}

This study developed a mechanical ventilation education program with a blended learning method for nursing students and verified its effectiveness. For the development of this program, a learner-centered ISD process was applied by thoroughly analyzing learners' educational needs, and feedback was obtained for each phase. As a result of the verification of this program, the experimental group participants improved their knowledge, self-confidence, and nursing skills performance level compared to the control group. Therefore, all effects were proven as hypothesized. This program contributed to enhancing nursing performance ability by including learners' actual practical activities and online learning. It is meaningful that knowledge and skills that students consider difficult and complex to obtain can be sufficiently learned through well-organized teaching methods such as blended learning. 
Regarding suggestions for the use of this program and subsequent research, first, longitudinal studies are needed in the future to confirm the long-term effects of educational programs. Second, it is necessary to conduct a program-effectiveness verification for nursing students located in various regions. Third, it is necessary to minimize the possibility of bias and error by conducting a randomized controlled trial.

\section{CONFLICTS OF INTEREST}

The authors declared no conflict of interest.

\section{REFERENCES}

1. Smeltzer SC, Bare BG, Hinkle JL, Cheever KH. Brunner \& Suddarth's textbook of medical-surgical nursing. 12th ed. Philadelphia, New York: Wolters Kluwer/Lippincott Williams \& Wilkins; 2010. p. 651-661.

2. Park KS, Hwang YY, Choi EH. The study of the nursing students' lived experience of clinical practice at the intensive care unit. Korean Journal of Adult Nursing. 2003;15(3):373-382.

3. Lewis SL, Dirksen SR, Heitkemper MM, Bucher L. Medical surgical nursing. 9th ed. Shin GR, Kim OS, Kwang YH, Kim NC, Kim YG, Kim YH, et al., translators. Seoul: Hyunmoonsa; 2019. p. 600-615.

4. Lynn-McHale Wiegand DJ, Carlson KK. AACN procedure manual for critical care. Vol. 1. 6th ed. Korean Association of Critical Care Nurses, translator. Seoul: Elsevier Korea; 2014. p. 280-365.

5. Lee MH. Effect of ventilator associated respiratory infection control education on perception, performance and nosocomial infection for critical care nurse [master's thesis]. Daejeon: Daejeon University; 2004. p. 1-50.

6. Kim KS, Lee SM. Effects of ventilator-associated pneumonia (VAP) control education on ICU nurses' infection control performance and incidence of pneumonia. Journal of Korean Critical Care Nursing. 2010;3(2):13-22.

7. Aloush SM. Nursing students' knowledge about ventilatorassociated pneumonia prevention guidelines: effectiveness of a teaching program. American Journal of Infection Control. 2017;45(5):544-546.

https://doi.org/10.1016/j.ajic.2017.01.025

8. Yang JJ. Effects of web-based multimedia contents for mechanical ventilator practice on knowledge and clinical competence of nursing students. Korean Journal of Adult Nursing. 2006; 18(2):231-239.

9. So YS, Bae YS, Kim YO, Kim SM, Kang HY, Choi JY, et al. Development of web-based multimedia contents for the critical care practice of nursing students through inter-college collaboration. Korean Journal of Adult Nursing. 2008;20(5):
778-790.

10. Choi YS. The development of web-based ventilator management education program. Journal of Korea Academia-Industrial cooperation Society. 2012;13(11):5284-5291.

https://doi.org/10.5762/KAIS.2012.13.11.5284

11. Jansson MM, Ala-Kokko TI, Ohtonen PP, Meriläinen MH, Syrjälä HP, Kyngäs HA. Human patient simulation education in the nursing management of patients requiring mechanical ventilation: a randomized, controlled trial. American Journal of Infection Control. 2014;42(3):271-276.

https://doi.org/10.1016/j.ajic.2013.11.023

12. Tallo FS, Vendrame LS, Baitello AL. Comparison of three methods for teaching mechanical ventilation in an emergency setting to sixth-year medical students: a randomized trial. Revista da Associacao Medica Brasileira. 2020;66(10):1409-1413. https://doi.org/10.1590/1806-9282.66.10.1409

13. Corbridge SJ, Robinson FP, Tiffen J, Corbridge TC. Online learning versus simulation for teaching principles of mechanical ventilation to nurse practitioner students. International Journal of Nursing Education Scholarship. 2010;7(1):article12. https://doi.org/10.2202/1548-923X.1976

14. Toro-Troconis M. Why we should pay more attention to elearning. Journal of Health Specialities. 2015;3(4):191.

15. Krathwohl DR. A revision bloom's taxonomy: an overview. Theory Into Practice. 2002;41(4):212-218.

https://doi.org/10.1207/s15430421tip4104_2

16. Morton CE, Saleh SN, Smith SF, Hemani A, Ameen A. Bennie $\mathrm{TD}$, et al. Blended learning: how can we optimise undergraduate students' engagement? BMC Medical Education. 2016; 16:195. https://doi.org/10.1186/s12909-016-0716-Z

17. Yeom GJ, Yang J, Kim HS. Development and effects of supplementary textbook about EKG for nursing students. Journal of Korean Academy Fundamentals of Nursing. 2020;27(3):268-276. https://doi.org/10.7739/jkafn.2020.27.3.268

18. Carey L, Dick W. Systematic design of instruction. 7th ed. Kim DS, Kang MH, Seol YH, translator. Seoul: Academy Press; 2009. p. 1-30.

19. Kim YC, Lee EC. An effect of blended action learning program on the self directed learning skills. Journal of Korea Contents Association. 2015;15(11):658-671. https://doi.org/10.5392/JKCA.2015.15.11.658

20. Kwon DB, Oh YJ, Park HM, Son JJ, Song SH. An exploring study on determining factors for college student's degree of educational satisfaction. Korean Journal of Educational Research. 2002;40(3):191-202.

21. Park SH, Ahn Y, Jung JY. A development of action learning program for enhancing core competence: focused on tourism and convention industry in Busan. Journal of Korean Association Educational Information and Media. 2005;11(4):95-124.

22. Littlejohn A, Pegler C. Preparing for blended e-learning. Ox- 
ford, UK: Routledge; 2007. p. 1-272.

23. McCutcheon $\mathrm{K}, \mathrm{O}^{\prime}$ Halloran $\mathrm{P}$, Lohan M. Online learning versus blended learning of clinical supervisee skills with pre-registration nursing students: a randomised controlled trial. International Journal of Nursing Studies. 2018;82:30-39.

https://doi.org/10.1016/j.ijnurstu.2018.02.005

24. Zhan X, Zhang Z, Sun F, Liu Q, Peng W, Zhang H, et al. Effects of improving primary health care workers' knowledge about public health services in rural China: a comparative study of blended learning and pure e-learning. Journal of Medical Internet Research. 2017;19(5):e116.

https://doi.org/10.2196/jmir.6453

25. Marchalot A, Dureuil B, Veber B, Fellahi JL, Hanouz JL, Dupont $\mathrm{H}$, et al. Effectiveness of a blended learning course and flipped classroom in first year anaesthesia training. Anaesthesia Critical Care \& Pain Medicine. 2018;37(5):411-415. https://doi.org/10.1016/j.accpm.2017.10.008

26. Shang F, Liu CY. Blended learning in medical physiology improves nursing students' study efficiency. Advances in Physiology Education. 2018;42(4):711-717. https://doi.org/10.1152/advan.00021.2018

27. Sheikhaboumasoudi R, Bagheri M, Hosseini SA, Ashouri E, Elahi N. Improving nursing students' learning outcomes in fundamentals of nursing course through combination of traditional and e-learning methods. Iranian Journal of Nursing and Midwifery Research. 2018;23(3):217-221. https://doi.org/10.4103/ijnmr.IJNMR_79_17

28. Moon H, Hyun HS. Nursing students' knowledge, attitude, self-efficacy in blended learning of cardio-pulmonary resuscitation: a randomized controlled trial. BMC Medical Education. 2019;19:414. https://doi.org/10.1186/s12909-019-1848-8

29. Lim SO, Lee MK. Development and application of video-audio media for prior learning simulation: focusing on neonatal respiratory distress syndrome nursing. Journal of Learner-Centered Curriculum and Instruction. 2017;17(7):441-458.

https://doi.org/10.22251/jlcci.2017.17.7.441

30. Yang MK. Exploring the meaning and conditions of experimental learning. Korean Journal of Educational Research. 2001; 39(1):167-196. 